\title{
Hypovolemic Shock Complicating Nephrotic Syndrome in a Child
}

\author{
by \\ LYDIA KOSNADI, ROCHMANADJI W., AG. SUMANTRI, \\ TRIMULYO, and M. ROFIQ ANWAR \\ (From the Department of Child Health and \\ Department of Pathology, Medical Faculty, Diponegoro University/ \\ Dr. Kariadi Hospital, Semarang)
}

\begin{abstract}
The fundamental abnormality in nephrotic syndrome is the structural and electrochemical changes that have been documented to occur in the glomerular basement membrane lead to proteinuria. It is the proteinuria itself which most likely causes hypoalbuminemia and associated complications such as infections, hypercoagulability and hypovolemia. Hypovolemia may cause postural hypotension, acute renal failure, circulatory collaps or sudden death.

An eleven-year-old boy was referred to the Child Health Department of Dr. Kariadi Hospital Semarang with a diagnosis of corticosteroid resistant nephrotic syndrome and acute renal failure. Physical examination showed a severely ill boy with general edema, shock, hemoconcentration, hypoalbuminemia, hypercholesterolemia, massive proteinuria and disturbed renal function.

The treatment consisted of infusion of dextrose $10 \%$ followed by human plasma and furosemide to restore plasma volume and enhance urine production. Two days later he was in better condition, normovolemia, slight edema, good diuresis, but his blood pressure increased, and ophtalmologic examination supported the diagnosis of grade I hypertensive retinopathy. Intravenous clonidine and furosemide were given and were very effective. Kidney biopsy revealed minimal lesion with slight proliferation.
\end{abstract}




\section{Introduction}

Nephrotic syndrome (NS) is a clinical state characterized by symptoms of massive proteinuria ( > 0.05-1.0 g/kg/day), hypoalbuminemia ( $<2.5 \mathrm{~g} / \mathrm{dl}$ ), hypercholesterolemia ( $>250 \mathrm{mg} / \mathrm{dl}$ ), and edema (Mc Every and Strife, 1985; Rance et al., 1979).

The pathogenesis of massive proteinuria in NS is based on the leakage of glomerular filtration to protein, due to structural and electrochemical changes in the glomerular basement membrane (Mc Every and Strife, 1985; Robson, 1983). Massive proteinuria which mostly consists of albumin, leading to hypoalbuminemia, results in the decrease of plasma osmotic pressure, thus

decreasing extracellular fluid reabsorption, and further develops into massive edema. The process is also followed by hypovolemia, which can be recognized by the increase of hematocrit value (Rubin, 1975; Chantler, 1970). Symptomatic hypovolemia may further develop into the most important complication of NS, as it may cause postural hypotension, acute renal failure, hypovolemic shock, and even sud den death (Barnett et al., 1978; Egan, 1967; James, 1976).

The purpose of this article is to report the successful treatment of a child suffering from hypovolemic shock complicating NS.

\section{Case Report}

An 11 years old boy, sent by the regency hospital with "corticosteroid resistant NS and acute renal failure" was admitted to the Dr. Kariadi Hospital, on October 22, 1984. On anamnesis, he had suffered from edema since 4 months, beginning at the palpebrae, spreading to the feet, and developing widely into general edema. The first hospitalization had been in the regency hospital, 21/2 months long, and he was afterward discharged in remission. Since one month he had been hospitalized again due to relapse of the disease. In this respect, the edema was refractory and during the last 3 days he had suffered from headache and vomited frequently. The amount of urine was also decreased.

Physical examination revealed an 11year-old boy with a body weight of $25 \mathrm{~kg}$, his height was $120 \mathrm{~cm}$, the temperature was $37^{\circ} \mathrm{C}$, palpatoric blood pressure $70 \mathrm{mmHg}$, pulse rate 160 /minute. The boy was alert, looked severly ill, had a moonface with $\mathrm{ml} / \mathrm{kg} /$ hour was given for 5 hours, followed by human plasma infusion of $20 \mathrm{ml} / \mathrm{kg}$ in 5 hours slowly; intravenous furosemide $2 \mathrm{mg} / \mathrm{kg}$ was given 30 minutes after the infusion of human plasma. Ten percent dextrose infusion $2 \mathrm{ml} / \mathrm{kg}$ /hour was then given as maintenance. Ampicillin $60 \mathrm{mg} /$ $\mathrm{kg} /$ day was administered to treat the bronchitis. Hypovolemic shock had thus been overcome on the first day of admission. On the second day of admission the blood pressure increased to $165 / 105 \mathrm{mmHg}$. On the third day the edema subsided and the patient vomited frequently, the blood pressure became $175 / 110 \mathrm{mmHg}$, and funduscopy revealed a grade I hypertensive retinopathy. Therefore the patient was referred to the Pediatric Intensive Care Unit. Ten percent of dextrose solution was infused 2 $\mathrm{ml} / \mathrm{kg} /$ hour as maintenance. Clonidine was administered (initial dose of $0.15 \mathrm{mg}$ in $10 \mathrm{ml}$ of $10 \%$ dextrose slow intravenously, followed by $0.75 \mathrm{mg} / 500 \mathrm{ml}$ infusion fluid as maintenance dose). Furosemide 2.5 $\mathrm{mg} / \mathrm{kg} /$ day, and ampicillin $60 \mathrm{mg} / \mathrm{kg} /$ day were given intravenously.

On the $5^{\text {th }}$ day of admission the blood pressure became normal. An open renal biopsy was carried out on the $9^{\text {th }}$ day, revealing minimal changes with slight membranoproliferation, meanwhile, the immunoperoxydase method showed IgG deposits on many parts of the tubuli, and IgA deposits on the capillary basement membrane.

On the $10^{\text {th }}$ day of admission the genera condition of the patient improved, his blood pressure was $120 / 80 \mathrm{mmHg}$, the total protein $4.54 \mathrm{~g} / \mathrm{dl}$, albumin $2.36 \mathrm{~g} / \mathrm{dl}$, globulin $2.18 \mathrm{~g} / \mathrm{dl}$, ureum $15.1 \mathrm{mg} / \mathrm{dl}$, creatinine $0.58 \mathrm{mg} / \mathrm{dl}$, there was proteinuria $(++)$, the Esbach reaction was 2 per- mil, and hyalin casts were still present. Electrocardiography revealed a normal pattern, and chest rontgenogram showed that the bronchitis had subsided. All these data showed that the impending acute renal failure, hypovolemic shock, and hypertension had been overcome.

The patient was then removed to the Child Nephrologic Ward. Classical treatment of prednison $2 \mathrm{mg} / \mathrm{kg}$ in three equal doses every day was instituted. Until 28 days of treatment no remission occurred, the patient had still slight edema, proteinuria $(++)$ and an Esbach of 2 permil. A single dose of cyclophosphamide 70 $\mathrm{mg}$ /day every morning was administered in combination with a single dose of prednison $2 \mathrm{mg} / \mathrm{kg}$ on alternating days. Eventhough until 6 weeks after this combined treatment had begun, no remission occurred. Cyclophosphamide was stopped and prednison tapered off. On the $120^{\text {th }}$ day of admission the patient was discharged from the hospital, and managed ambulatorily at the Out Patient Department. On discharge the child was alert, with slight edema on both legs, had a moonface, the blood pressure $120 / 80 \mathrm{mmHg}$. Blood examination revealed a total protein of $6.29 \mathrm{~g} / \mathrm{dl}$, albumin $3.75 \mathrm{~g} / \mathrm{dl}$, globulin $2.54 \mathrm{~g} / \mathrm{dl}$, cholesterol $386 \mathrm{mg} / \mathrm{dl}$.

Urine examination showed proteinuria $(++)$, Esbach 2 permil, no hyalin cast. Other laboratory values were within normal limits. The treatment on discharge was prednison (tapering off dose), clonidine 3 x $1 / 2$ tablet, spironolactone $1 / 2$ tablet every morning. To the parents, elaborate information was given about their son's disease, the poor prognosis, the diet and hygienic care at home, and the aims of regular follow-up visit to the Out Patient Department. 


\section{Discussion}

Hypovolemic shock as a complication of NS has long been known and studied by scientists. It is important to keep it in mind as it may cause sudden death. It is assumed that the "pituitary-adrenal pathway" of the patient has been hyporesponsive due to the prolonged adrenocortical treatment (Egan, 1967; Rubin, 1975). The pathogenesis of symptomatic hypovolemia is not merely due to the deficiency of the total body fluid and electrolytes (eg. restriction of water intake, excessive diuretic treatment, or both simultaneously), since the excessive extravasation of water and electrolytes into the interstitial space may play an important part on the decrease of intravascular fluid volume (Norman, 1983). The "status quo" condition during the last month of treatment in the regency hospital confirmed the above mentioned theory.

On the arrival at the Dr. Kariadi Hos pital, the patient clinically showed the symptoms of shock, supported by the high value of hematocrit $(55 \%)$, hemoglobin concentration $(14.6 \mathrm{~g} / \mathrm{dl})$, and low centra venous pressure $(3.5 \mathrm{~cm}$ of water).

It seemed that the hypovolemic state had existed for quite a long time, thus leading to an "impending renal failure" (serum ureum $55.7 \mathrm{mg} / \mathrm{dl}$ and creatinine 2.33 $\mathrm{mg} / \mathrm{dl})$.

The treatment of hypovolemic shock is usually done by giving $20 \mathrm{ml} / \mathrm{kg} / \mathrm{hour}$ of normal saline solution until the circulation returns to normal (Norman, 1983). But to this patient, whose kidney function had been impaired and the electrolyte concentrations had not been detected yet, the correct decision is to give $10 \%$ dextrose solution, $4 \mathrm{ml} / \mathrm{kg} / \mathrm{hour}$ which seemed to be able successfully to overcome the shock within 5 hours, resulting in a diuresis of 200 $\mathrm{ml}$. The increase of hematocrit value, low sodium content in the urine, severe hypoalbuminemia, and/or refractory edema are indication to give human albumin intravenously, or low salt albumin $(0.5-1.0 \mathrm{~g} /$ $\mathrm{kg}$, given within 2-4 hours), followed 30 minutes later by furosemide $(0.5-2.0 \mathrm{mg} /$ $\mathrm{kg}$, slow intravenous) (Barnett et al., 1978; Chantler, 1970; Vaughan et al., 1979). This has been the most physiological and effective method to reduce edema. Since there may be a sudden increase of intravascular fluid volume, the patient should be closely monitored toward the side effects of hypertension, heart failure, and pulmonary edema (Mc Every and Strife, 1982). The patient, whose $\mathrm{Ht}$ was $55 \%$, urine $\mathrm{Na} 21$ $\mathrm{mEq} / 1$, with hypoalbuminemia $(2.13 \mathrm{~g} / \mathrm{dl})$ and refractory edema, fulfilled the indication for giving plasma and furosemide. It was evident that by transfusing human plasma $10 \mathrm{ml} / \mathrm{kg}$ during 5 hours followed by furosemide $2 \mathrm{mg} / \mathrm{kg}$, an effective diuresis (1000-1300 ml/day) could be obtained without any complications. The edema subsided within 2 days. Membranoproliferative glomerulonephritis is a glomerular disease especially found in older children and adults. The general symptoms are edema and hematuria. Approximately $30 \%$ of the cases are hypertensive, besides having impairment of kidney functions (33\%), nephrotic syndrome $(44 \%)$, decrease of serum C-3 concentration (74\%) and C-4 (34\%). Treatment with corticosteroid, cytostatics (cyclophosphamide, azathioprine), and even dipyridamole plus anticoagulant do not give satisfactory results yet (Gauthier et al., 1982; White, 1978).

In this patient, renal biopsy showed a pattern of minimal changes with slight membranoproliferation. Considering his clinical course and the result of prednison plus cyclophosphamide treatment, and the fact that he did not achieve total remission, it was obvious that the patient's disease was in accordance to the above mentioned review. The existence of epithelial crescents, uremia, and gross hematuria in the early stage of the disease reveals "no good

\section{Summary}

A case of successful treatment of an 11 year-old boy with hypovolemic shock as a complication of nephrotic syndrome has been presented. The diagnostic procedure, management, treatment, and the prognosis

\section{REFERENCES}

1. BARNETT, H.L.; SCHOENEMAN, M. BERNSTEIN, J.; EDELMANN JR, C.M.: Th nephrotic syndrome; in Edelman et al., Pediatric Kidney Disease, pp. 679-695 (Little Brown, Boston 1978).

2. CHANTLER, C.: The Kidney; in Godfrey and Baum, Clinical Pediatric Physiology, pp. 356-398 (Blackwell Scient. Publ., Oxford 1970).

3. COLE, B.R.; VALDES, A.J.: Pathology and Pathophysiology of Proteinuric Glomerular Disease; in Klahar, The Kidney and Body Fluid in Health and Disease, pp. 399-440 (Plenum Med. Book, New York 1983).

4. EGAN, T.J.: Shock as a Complication of the Nephrotic Syndrome. Am J. Dis. Child., 113 : 364 (1967).

5. GAUTHIER, B.; EDELMANN JR, C.M. BARNETT, H.L.: Nephrology and Urology for the Pediatrician pp. 123-139 (Little Brown, Boston 1982).

6. HOLleRMAN, C.E.: Pediatric Nephrology. pp. 291-327 (Toppan, Singapore 1979).

7. JAMES, J.A.: Renal Disease in Childhood. pp. 214-240 (Mosby, Saint Louise 1976).

8. LEVINA, D.L.; PERKIN, R.M.: Shock; in a Practical Guide to Pediatric Intensive Care, pp. prognosis".

The clinical course of the disease will be progressive leading to a chronic rena failure, and it may finally develop into an "end stage of a renal disease'" within 6-10 years (Cole and Valdes, 1983; White, 1978 , in which chronic dialysis or kidney transplantation is indicated (White, 1978).

of the disease have also been discussed.

The pathologic finding of the pattern of minimal changes with slight membranoproliferation, suggests that the prognosis is not good.

68-79 (Mosby, Saint Louise 1984)

9. MC EVERY, P.T.; STRIFE, C.F.: Nephrotic Syndrome in Childhood. Pedait. Clins N. Am. 89 (4) : 875-894 (1982)

10. NORMAN, M.E.: Renal and Electrolyte Emergencies; in Fleister G.R. and Ludwig, S, The Textbook of Pediatric Emergency Medicine, pp. 415-459 (Williams \& Wilkins, Be Medicine, pp.

11. RANCE, C P ; ARBUS, G.S.; BALFE, J.W. Management of the Nephrotic Syndrome in Children. Pediat. Clins N: Am. 23 : 735-750 (1976).

12. ROBSON, M.A.: Edema and Edema-forming states; in Klahr, S, The Kidney and Body Fluids in Helath and Disease, Pp. 119-147 (Plenum Med. Book, New York 1983).

13. RUBIN, M.I.: Nephrotic Syndrome; in Rubin, and Barrat, Pediatric Nephrology, pp. 454-498 (Williams \& Wilkins, Baltimore 1975).

14. VAughan, V.C.: Nelson Textbook of Pediatrics, $11^{\text {th }}$ ed. pp. 1494-1498 (Saunders, Philadelphia 1979).

15. WHITE, R.H.: Membranoproliferative Glomerulonephritis; in Edelman et al., Pediatric Kidney Diseases, PD. 660-679 (Little Brown, Boston 1978). 